\title{
LA LUCHA ENTRE ESPAÑA Y PORTUGAL POR LA OCUPACION DEL ESPACIO: UNA VALORACION ALTERNATIVA DEL TRATADO DE SAN ILDEFONSO DE 1777
}

\author{
Lic. Marcela Viviana Tejerina \\ Gabinete de Investigación de Historia Americana y Argentina
}

RESUMO: A ocupação definitiva da Colônia de Sacramento c as disposiçōes do Tratado de São Ildefonso deram uma fisionomia diferente à tradicional e permanente interaçāo de lusitanos c espanhóis na área rio-platense. Essas mudanças provocaram a inevitável reação daqueles que viam desmoronar a estrutura que tinha sustentado suas atividades até esse momento. A proposta deste artigo consiste em analisar o processo de adequação e readaptação daqucles indivíduos a cssa situação, com a finalidade de descobrir os mecanismos utilizados para adaptar-se a mesma c gerar novas formas de relacionamento.

ABSTRACT: The definite settement of the Colonia do Sacramento and the resolutions of San Ildefonsos' Treaty brought distinct features to the traditional and permanent Hispanic-Lusitanian interaction in the Rio de la Plata region. These changes triggered the inevitable reaction of those affected by the collapse of the establishment which had sustained their activitics until that moment. This present article analyzes the process of adjustment and readjustment of these individuals to this situation, with the objective of comprehending Spanish and Portuguese mechanisms of adaptation and the unfolding of new kinds of association.

PALAVRAS-CHAVE: Rio da Prata, Tratado, Interação, Hispano-lusitano, Readaptaçāo

KEYWORDS: Rio de la Plata, treaty, interaction, Hispanic-Lusitanian, readjustment

\section{Introducción}

La cuenca del Plata fue el cpicentro de los continuos intentos de Portugal por extender sus fronteras sobre las posesiones españolas de ultramar. Ese espacio geográfico de contornos imprecisos que recibía el nombre de Paracuaria representó una preocupación constante para el gobierno hispánico, pues los portugueses tendieron, desde siempre, a convertir al Río de la Plata en el límitc natural entre sus poscsiones y 
las castellanas. Toda la zona de influencia de este río constituyó un verdadero espacio fronterizo en el que, permanentemente, interactuaron los intereses de ambas naciones ibéricas $y$, como todo territorio de frontera, fue escenario del desenvolvimiento de diversas formas de vinculación a lo largo de la historia de la región. Los lusitanos, consecuentes en sus intentos de ampliar su área de dominación efectiva, ya durante la unión del gobierno peninsular habían traspasado con creces los límites impuestos por el Tratado de Tordesillas, posibilitándose la presencia efectiva de una gran cantidad de portugueses en diversos puntos de la gobernación (CANABRAVA, 1984). Luego de la restauración en 1640, la expansión continuo de la mano de los "bandeirantes" y alcanzó su punto culminante en 1680 con la fundación de Colonia de Sacramento frente a la ciudad porteña. La existencia de este establecimiento comprometió las ya difíciles relaciones entre las dos naciones y dio lugar a la consolidación de una antigua y muy frecuentada vía de comunicación por los puertos de Buenos Aires y Montevideo: el comercio clandestino (BARBA, 1980).

Desde 1680 y hasta muy avanzado el siglo XVIII, el contrabando rcalizado descle dicho er.clave sirvió a los fines de obtener el metálico tan ansiado. Su traspaso definitivo a la corona española en 1777, la firma del Tratado de San Ildefonso en el mismo año y la consecuente paz entre ambas coronas, a su vez, determinaron un significativo reacomodamiento en la puja por el predominio en la región.

Estos cambios provocaron la inevitable resistencia de quienes veían derrumbarse la estructura que tradicionalmente sostenía sus actividades. Como reacción, se apresuraron a abrir nuevos caminos para el usufructo de sus beneficios y así se fueron modificando las relaciones económicas con los sectores locales, que comenzaron a adquirir una fisonomía diferente. Por consiguiente, la propuesta del presente trabajo consiste en analizar este proceso dc adecuación, reacomodamiento y ajuste de los individuos, frente a las nuevas reglas de juego impuestas desde el gobierno central, a fin de determinar y describir las pautas de relación que se generaron sobre la base de este "nuevo orden" y descubrir los mecanismos utilizados para adaptarse al mismo.

El análisis de estos temas debe trascender el nivel regional para integrarlos a los procesos americano, peninsular y europeo, signados por un clima internacional que se complicaba progresivamente. Las potencias europeas, en lucha por la hegemonía, habían ido definiendo una red de alianzas en la que España se apoyaba en Francia, mediante el sostenimiento de los Pactos de Familia. Portugal, por su parte, se había convertido desde el Tratado de Metuen en socia y aliada incondicional de Inglaterra. La política de alianzas funcionaba como una verdadera garantía de supervivencia de los reinos ibéricos como naciones colonizadoras' y, en la lucha por el poder, los territorios de ultramar jugaron un importante papcl. Estrategias que superaban el planteo puramente localista determinaron su futuro $y$, en ocasiones, los rescataron de un destino oscuro y marginal para ubicarlos en la senda que los conduciría al protagonismo.

En este contexto, el Río de la Plata fue objeto de importantes transformaciones internas en el orden político y económico que, hacia el último cuarto del siglo XVIII, promovieron su desarrollo integral. Inextricablemente unida a la expedición de Ceballos se determinó la creación del Virrcinato del Río de

1. Fernando A. Novais señala al respecto que *... el desfasaje entre la posición política y económica de las ınetrópolis ibéricas en el cuadro de equilibrio europeo y la extensión e importancia comercial de sus dominios ultramarinos sólo se pudo inantener hasta el fin del siglo XVIII gracias a la rivalidad entre las potencias ascendentes, Inglaterra y Francia." NOVAIS, Fernando A. Pormgal y Brasil en la crisis del antiguo sistema colonial (1777-1808). EJitora Hucitec, San Pablo, 1989. 
la Plata. Al poco tiempo, la promulgación del Reglamento y Aranceles Reales para el comercio libre de España e Indias contribuyó a promover la aceleración de los cambios tendientes a modificar sus basamentos político-administrativos y su estructura económico-social.

Estas reformas, sumadas a la ocupación definitiva de Colonia y a la existencia de un convenio internacional que le daba marco legal, podrín haber significado para el gobierno español la finalización del antiguo y arraigado problema generado por la presencia activa de los portugueses. Sin embargo, no se tuvieron en cuenta otros factores tales como las futuras exigencias geopolíticas y estratégicas de una coyuntura internacional cada vez más comprometida $o$, lo que fue igualmente decisivo, las alteraciones que sc producirían en cl ámbito de las relaciones de portugueses y españoles en la región.

Es en este marco general que el Tratado de San Ildefonso logró una relevancia singular pues, más allá del problema limítrofe, propició directa o indirectamente el surgimiento de nuevas condiciones favorables para la afirmación de los intereses de unos $y$ otros en la zona.

\section{El ajuste frente al «nuevo orden»}

El primero de octubre de 1777 se firmó en San Ildefonso el Tratado prcliminar hispano-portugués de paz y límites. Según sus cláusulas, los fundamentos de la demarcación debían remitirse y ajustarse al Tratado de Madrid (1750). En líneas generales pasaban a jurisdicción española la Colonia del Sacramento, los Sicte Pueblos de las Misiones Orientales del Uruguay y el territorio al Norte de Castillos Grandes hasta la laguna Mirim y sus vertientes. Además, España manıcnía la cxclusividad en el tráfico de los Ríos de la Plata y Uruguay y obtenía la soberanía sobre las Islas Annobon y Fernando Poo. Portugal, por su parte, confirmaba sus derechos so- bre las provincias de Santa Catalina y Río Grande. Asimismo sc determinaba la existencia de zonas neutrales en las que ninguna de las partes podía penetrar, poblar o hacer comercio y se establecía la formación de una comisión mixta que debería trasladarse a América para fijar las fronteras definitivas entre ambas naciones (Tratado Preliminar..., 1970, p. 213 a 237).

Las valoraciones de la historiografía respecto a la importancia de este documento difieren de acuerdo a la perspectiva de análisis sobre la que se centren. Sin embargo, la mayor parte de los autores lo analiza en función de la problemática de la demarcación de fronteras. Mientras algunos señalan su importancia para la fijación de los límites entre ambos reinos (CÁRCANO, 1972, p. 179 a 181), otros lo consideran de gran perjuicio para España, en tanto y en cuanto perdió las provincias de Santa Catalina y Río Grande y accedió a la neutralidad de algunas zonas, sin advertir que complicaría la demarcación y serviría de refugio de ladrones y contrabandistas (SILIONI, 1964. p. 107 a 109). Desde la perspectiva brasileña la visión del tema es distinta. Para Manoel Mauricio de Albuquerque el tratado respondí́ a la política expansionista de España: "El expansionismo español fue, en parte, facilitado porque Inglaterra se encontraba envuelta en la Guerra de Independencia contra los colonos norte-americanos (1776-1783). Sin este apoyo externo y debilitado por la política anticolbertista de D. María I, el gobierno portugués fue forzado a firmar el Tratado de San Ildefonso en 1777" (ALBUQUERQUE, 1984. p. 205). Desde el punto de vista del desenvolvimiento de la política internacional, por otro lado, tuvo importantes connotaciones para los sucesos que sobrevendrían a principios de la década siguiente. Sobre sus bases se firmaría el 11 de marzo de 1778 el Tratado de El Pardo, de amistad, garantía y comercio entre España y Portugal, comprometiéndose ambas naciones a no entrar en guerra una contra otra. 
De esta forma, España se aseguraba la neutralidad de los lusitanos en el inminente conflicto que lo iba a enfrentar con Inglaterra al apoyar la independencia de las colonias de Norteamérica.

No obstante estos distintos enfoques, la mayoría de los estudiosos coincide en destacar que, a pesar de la firma del tratado, la divergencia de intereses y ambiciones de ambas naciones sobre el área rioplatense se mantuvo de tal forma que nunca se llegó a una solución concluyente del problema. Las comisiones de límites debieron enfrentarse a diversos problemas que obstaculizaron aún la constitución de las mismas y el gobierno portugués tendió a dilatar la concresión de la demarcación definitiva. Dice Cárcano al respecto: "Las comisiones hallan toda clase de dificultades para constituirse, por falta de técnicos e instrumental adecuado, por el distinto criterio para iniciar el trabajo, por las instrucciones vacilantes de Madrid, las chicanas de Portugal y las contradicciones que encuentran en los documentos que deben servir de base para la demarcación. Sólo dos comisiones trabajan conjuntamente. El resultado final es muy deficiente. Los portugueses, hábiles y tenaces en demorar el cumplimicnto tel tratado, finalmente abandonan la empresa. El mayor bencficio de este gran esfuerzo son los informes, estudios, memorias y diarios que escriben sus más destacados comisionados" (CÁRCÁNO, 1972, p. 180).

Extendiendo el análisis más allá del planteo geopolítico y estratégico, la lectura de este documento permite incursionar en el ámbito particular de aquellos individuos que, por una u otra razón, se vieron involucrados en los cambios y transformaciones que se produjeron como consecuencia de su implementación.

Las particularidades del área platina hicieron que su elaboración pretendiera cumplir con la doble finalidad de solucionar el problema limítrofe y de terminar con las actividades ilegales que se desarrollaban en la región. En el artículo XVI de su texto se hacfa referencia al compromiso que asumían las dos naciones ibericas para conservar la “... recíproca seguridad y perpetua paz, y tranquilidad de ambas naciones, y el total externinio de los contrabandos, que los súbditos de la una puedan hacer en los dominios, o con los vasallos de la otra" (Ibidem, p. 230 a 231). Por tal razón se establecía que, en caso de que se aprehendiere a cualquiera de estos individuos comerciando en forma ilegal, sería castigado en su persona y bienes con las penas impuestas por las lcyes de la nación que le hubiese capturado. En el artículo XVII se incluía bajo sanciones similares a todos aquellos que incursionaran en el territorio o en los ríos que no fueran propios de su nacion, aunque se exceptuaba a los que arribasen a puerto y territo. rios ajenos por necesidad y urgencia o por comisión oficial de su respectivo país (Ibidem, p. 231 a 232).

Además de estas especificaciones, había una serie de cláusulas destinadas a aclarar y solucionar las diferentes situaciones particulares que se pudiesen presentar. Por el artículo II se ordenaba que los españoles y lusitanos que se hubieran hecho prisioneros en mar o en tierra fueran puestos en libertad, sin otra condición que la de asegurar el pago de las dcudas que hubieran contraído en el país en que se hallasen. Más adelante se precisaba que tanto los habitantes como los oficiales y soldados vasallos de Portugal que se encontraban en Colonia del Sacramento, isla de San Gabricl u otro cualquier territorio que pasaba a depender de la corona española, tendrían la libertad de retirarse o de permanecer en el lugar con sus efectos y mucbles. Por otro lado, cl gobernador, oficiales y soldados de la guarnición de Colonia gozarian de la facilidad de poder vender sus bienes raíces antes de abandonar la zona. Estas libertades y derechos se hacían extensivas a los habitantes, oficiales y soldados españoles que estuvieran en alguno de los establecimientos cedidos o renunciados en favor de la corona de Portugal (Ibidem, p. 219 a 237 y 224 a 225 ). 
El encargado de iniciar las diligencias para la restitución de los prisioneros portugueses que se hallasen en las provincias españolas $y$, a su vez, efectivizar las disposiciones del Tratado de San Ildefonso en torno a los vecinos de Colonia fue el Virrey Cevallos. Este debía resolver, además, las cuestiones planteadas por los mismos pobladores de las zonas en conflicto. En virtud de este tema se trató de tomar todas las precauciones a fin de facilitar el transporte de aquellos que quisiesen volver a su lugar de origen, previo pago de todas sus deudas en el territorio restituido. Al mismo tiempo, se permitió que los que quisiesen quedarse pudieran decidirlo voluntariamente.

A pesar de estas precauciones, sobre la marcha de los acontecimientos se comenzaron a presentar dificultades. Algunos portugueses que decidían abandonar Colonia tenían la pretensión de que se les pagara por el valor de sus casas; otros intentaban acarrear su ganado o decidían llevarse con ellos a su esposa e hijos españoles.

Si bien estas solicitudes no parecen descabelladas, significaban un problema para los representantes reales pues daban lugar a situaciones no previstas por la ley. Por tal razón, cl Virrey Vertiz no vaciló en denegar todos aquellos pedidos que no estuvicran comprendidos en las ordenanzas reales.

Hacia fines de 1781 se debía resolver, además del regreso de los pobladores a sus lugares de origen, la entrega de prisioneros y la restitución de las embarcaciones y cargas apresadas durantc cl conflicto. El Virrey Vértiz daba cuenta minuciosa de lo actuado en tal sentido, afirmando haber tomado las previsiones necesarias para poner fin a «... tan dilatado negocio, diferido a la verdad contra todos mis estímulos y condescendencia, por una progresiva deducción de nuevos artículos y disputas, que ha suscitado este comisionado Portugués» (Memorias de los Virreyes..., 1945, p. 103).

Los problemas de la administración española derivados de estas circunstancias no terminaban aquí. A la falta de cooperación por parte de los enviados del gobierno portugués, debían sumarse las distintas situaciones originadas en el aplazamiento de la solución a tan engorroso asunto que. por su parte, podían convertirse en excusas y pretextos para enmascarar algunas actividades ilícitas.

Así, por ejemplo, en febrero de 1780 una de las naves portuguesas que tenía que conducir la artillería y demás efectos que se debían entregarse a aquel gobierno hizo su aparición con el añadido de una carga de negros. Este hecho planteó grandes desacuerdos entre los representantes del gobierno virreinal. El administrador de la real Aduana indicó al intendente que se permitiese la venta de los mencionados negros porque "... la contemplaba útil, coincidía con algunos artículos del tratado preliminar, y evitaba el fraude de los referidos derechos" (Ibidem, p. 110). En el otro extremo, el defensor de Real Hacienda, los dos abogados fiscales, el tribunal de cuentas y el asesor del Virrcinato dictaminaron la ilegalidad de tal medida. Si éstos se fundamentaban en las prohibiciones legales que impedían de plano la venta de dichos negros en la plaza comercial rioplatense, el administrador de la aduana alegaba la conveniencia de su introducción para los intereses del virreinato, justificando su opinión en lo dispuesto por el Tratado de San Ildefonso ${ }^{2}$. Finalmente el Virrey permitió la venta de los negros c informó al gobierno portugués que su “... condescendencia con los oficiales, que había remitido era solo en obsequio de la buena armonía que procuraba se radicase entre ambos" (Memorias de los Virteyes..., 1945, p. 110). Otra fue su explicación al monarca español, aludiendo tanto a las connotaciones diplomáticas del problema como, fundamentalmente, a la necesidad de satisfacer las demandas de los

2. Seguramente aquí $\mathrm{el}$ administrador de la Real Aduana se refería a los artículos XVI y XVIl, que han sido comentados oportunamente. 
comerciantes del virreinato. Informado el rey de todo lo dispuesto, la decisión tomada por la máxima autoridad rioplatense fue aprobada por Real Orden del 14 de marzo de 1781.

\section{Algunas cuestiones colaterales}

La decisión tomada por el Virrey Vértiz acerca de permitir la venta de la carga negrera respondía, indudablemente, a los requerimientos, en todo el territorio virreinal, de mano de obra para la agricultura y la minería. Además había que sumar los efectos producidos por la paralización del comercio entre España con sus colonias, como consecuencia de la guerra desatada contra Inglaterra el 23 de junio de 1779.

El inicio de este conflicto, originado en el apoyo brindado por el gobierno peninsular a las colonias norteamericanas en su lucha por la independencia, obstaculizó la plena vigencia del Reglamento y aranceles reales para el comercio libre de España e Indias del 12 de octubre de 1778. Su prolongación hasta avanzado el año 1783, y sus repercusiones en el ámbito de las comunicaciones y el comercio entre la metrópoli y sus posesiones de ultremar, obligó a España a implementar una serie de medidas alternativas destinadas a lograr soluciones de emergencia ante la crisis desatada (SILVA, 1993).

La intervención lusitana en el comercio rioplatense fue una constante durante el período que duró el conflicto bélico con Inglaterra. El gobierno espa$\bar{n}$ ol se vio en la necesidad de utilizar la neutralidad de los portugueses como una vía alternativa para el comercio. Durante el mismo período y aún durante la posguerra, el tráfico negrero desde el Brasil fue un excelente punto de partida para todo tipo de transacciones mercantiles con el Río de la Plata. Los negros que se conseguían en dicha plaza cran relativamente baratos y esa vía de comercialización suministraba excelentes oportunidades para el contrabando (STUDER, 1958, p. 263 a 271).
Estas circunstancias sirvieron de marco para el desarrollo de distintas formas de vinculación mercantil entre lusitanos y españoles.

Don Diego Cantero, vecino de Buenos Aires y Capitán de las Milicias de Potosi, en marzo de 1785 habra sido favorecido con un permiso para conducir 600 negros al Río de la Plata y, en el viaje de retorno, trasladar cueros y otros frutos de la jurisdicción del Plata. Los negros se debían transportar desde el Brasil y en navios portugueses bajo la "...indispensable condición de no llevar cfecto, ni género alguno con los negros, bajo la pena de comiso..." (Documentos para la Historia Argentina, 1915, p. 280-281). Pese a estas advertencias, en 1786 se informaba que Cantero había arribado a Montevideo en la Zumaca Portuguesa Nuestra Scñora de los Dolores, su capitán Antonio Pereyra, llevando a su bordo ciento sesenta negros, varios efectos, y diferentes sujetos extranjeros con el fin de desembarcar y quedarse en el árca. En la causa que se le siguió por este ilícito se demostró que Cantero mantenía negocios con varios comerciantes de la ciudad de Bahía de Todos los Santos, tales como Juan Manucl Martínez de Acosta, Manuel de Silva Fernandez y Miguel José de Araujo (A.G.N., 33-3-8). Asimismo, en cl grueso expediente que se originó a raíz de estas actividades fraudulentas sc inculpó no sólo a Cantcro sino, también, al portugués Antonio Pereyra de los Santos, capitán de la zumaca lusitana, Juan de Silva Cordeiro, quien cra de la misma nacionalidad y actuaba como el sobrecargo de la embarcación, y el comerciante Custodio Antonio de Oliveira. Estos tres fueron procesados y acusados por el fiscal de su majestad en virtud de "... las graves penas en que por derecho han incurrido, y a que también están sujetos los portugueses por las leyes y tratados de Paz últimamente ajustados entre las dos cortes de España y Portugal con expresa condenación de costas" (A.G.N., 33-3-8 y 33-4-2).

Informado de estos hechos, el marqués de Sononra indicaba actuar con todo el rigor del dere- 
cho, imponiendo todas las penas con que se había conminado en la concesión del permiso.

Si en esta ocasión la administración española invocaba el Tratado de San Ildefonso para castigar el comercio ilegal cometido por un grupo de portugueses, el mismo documento había servido con anterioridad a las autoridades virreinales para justificar la implementación de una medida que no estaba enmarcada en la legislación, pero que era altamente provechosa para los intereses económicos rioplatenses en una época de conflictos. Este criterio particular para aplicar la ley habla a las claras del pragmatismo de las autoridades virreinales que se encontraban en la creciente necesidad de adaptar las normas a las demandas concretas de su tcrritorio, en el marco de una cada vez más confusa y cambiante coyuntura política internacional.

Los condicionamientos que rodeaban las decisiones gubernamentales justificarian, de alguna forma, la continua injerencia de los portugueses en el comercio lícito e ilícito rioplatense en los tiempos inmediatamente postcriores a la firma del Tratado de San Ildefonso. Sin embargo, no podemos dejar de resaltar que la misma administración española tenía graves deficiencias y presentaba amplios resquicios por los que se filtraban los lusitanos en busca de un provechoso intercambio. Es sabida y comprobada la asidua participación de las autoridades locales en diversas actividades fraudulentas que los vinculaban con los portugueses. Pero lo más grave es que, en ocasiones, los intereses lusitanos actuaban desde el mismo seno de la administración.

Tal fue cl caso de Don Manuel Cipriano de Melo, quien había actuado como piloto y práctico del Río de la Plata bajo las órdenes de Cevallos y Vértiz, para luego revistar como Teniente del Comandante del Resguardo del Pucrto de Montevideo. De él escribió un historiador: "No había sido virrey, ni gobernador, ni integrante del Cabildo, ni terrateniente, pero sí jefe de la vigilancia del tráfico ilegal de mercaderías, marino avezado, a ratos contrabandista, comerciante, empresario teatral, incansable escritor de cartas, notorio integrante de la masonería, caudillo, rico, generoso ... y por encima de todo, portugués, hijo de Ja misma Lisboa" (BENTANCUR, 1985, p. 8).

Su vida fue una gran aventura y sólo sus relaciones con distintas jerarquías de la burocracia colonial le permilicron esquivar, cn la mayoría de los casos, el rigor de la ley. El probadamente asombroso usufructo que este lisboeta hizo de las actividades clandestinas desde su puesto (A.G.N., 33-4-5), sólo fue posible en el marco de la connivencia de otros funcionarios. El mismo Virrey Loreto denunciaba "...las cualidades de los Comandantes que había en el resguardo, Ortega y Melo su segundo, y del Administrador Tesorero que tenía la Real Aduana de esta Capital, Mesa; malversadores todos de sus oficios y negociantes al mismo ticmpo que con socios de otras personas con valores muy crecidos del Erario de S.M..." (Memorias de los Virreyes.... 1945, p. 262).

A pesar de estas denuncias y no obstante las causas que se iniciaron en contra de Melo como consecuencia de sus dobles actividades (1788-1791), el mismo gobierno español contribuiría a su permanencia en el cargo. Por Real Orden del 16 de octubre de 1788 cra nombrado vasallo de la corona española, en posesión de todos los privilegios concedidos a los naturales del reino español y con derecho a mantener el puesto que se le había conferido. Esta decisión se fundamentaba, según el texto del documento, en los artículos $3^{\circ}, 7^{\circ}$ y $9^{\circ} \mathrm{del}$ Tratado firmado en San Ildefonso en octubre 1777 y “...en los méritos y servicios que acreditó haber ejeculado el nombrado Don Manuel Cipriano de Melo..." (A.G.N., 30-7-5).

\section{Conclusiones}

Si bien el Tratado de San Ildefonso pretendió otorgarlc una solución legal y definitiva a la problemática gcopolítica y estratégica que giraba en torno 
al espacio fronterizo rioplatense, los hechos demostraron que la Corona Española no supo aprovechar en la práctica lo que había ganado en los papeles. Los designios políticos emergentes de los órganos gubernativos lusitanos, sumados a la acción de los particulares en la zona, siempre tendieron a usufructuar legal o ilegalmente las posibilidades económicas de la región platina. Como bien explica un estudioso de la diplomacia luso-brasileña en el Río de la Plata: “... el gobierno de Portugal y sus autoridades en el Brasil, aprovechándose de la habitual indiferencia hispana, del poco interés prestado por el gabinete de Madrid a comarcas apenas habitadas y muy poco conocidas, habían ido ensanchando los límites del Brasil, con detrimento de los del virreinato de Buenos Aires..." (SILIONI, 1964. p. 108). Esta expansión fue complementada posteriormente con la incorporación de los pueblos de las Misiones orientales al dominio portugués luego de finalizada la Guerra de las Naranjas. ${ }^{3}$

Es evidente que la corona española no opuso una clara y contundente política que obstaculizara real y definitivamente la penetración de los intereses lusitanos. Además queda claro que no tivo el apoyo ni de la generalidad de los representantes de la administración en la zona, ni de los mismos pobladores que se beneficiaban de la situación.

Los casos analizados a lo largo del trabajo demuestran que los vasallos de ambas coronas encontraron en la normativa pautada en San Ildefonso en el año 1777 , un respaldo y una justificación para conti-

3. La llamada guerra "de las naranjas", de cona duración, permitio a los lusitanos apoderarse de los pueblos de las Misiones orientales mientras que, curiosamente, se comprometían a cerrar sus puertos a Inglaterra. España, por su parte, quedaba en posesión de la plaza portuguesa de Olivenza. Este desenlace había sido favorecido nuar interactuando en la region. Lo que tendría que haber significado un freno a la presencia lusitana en el Río de la Plata, se convierte en un factor propiciatorio más. Las normas fijadas en el documento en cuestión permitieron que muchos portugueses se quedaran residiendo en los territorios que pasaban a la jurisdicción española, junto con todas sus pertenencias. Algunos de estos hombres, como hemos visto. aún ocuparon puestos de vital importancia dentro de la estructura gubernamental, utilizando para su provecho las ventajas que esta situación ofrecía.

Simultáneamente, distintas circunstancias derivadas de la firma del tratado dieron pie para la introducción de los intereses comerciales lusitanos en el área rioplatense bajo diversas formas. El proceso de entrega de prisioneros y restitución de embarcaciones que siguió a la resolución de la paz enmascaro, en algunas oportunidades, irregularidades tales como la introducción de mercadería ilícita. La recientemente lograda paz entre las dos naciones ibéricas aseguró, por otra parte, la neutralidad portuguesa en el conflicto entre España y Gran Bretaña. Esto le dio a sus súbditos la oportunidad de sacar pingües ganancias de la utilización de sus barcos y hombres para la comunicación entre la península y sus colonias mientras duró el enfrentamiento. Sumado a estas circunstancias, el mismo tráfico de negros fue un excelente punto de partida para transacciones de todo tipo.

En el marco de estos hechos, el tratado de San Ildefonso tuvo una insospechada relevancia ya que,

por el acuerdo que se estaba elaborando entre ingleses y franceses: la "Paz de Amiens" del 25 de marzo de 1802. Cfr. CORTESĀO, Jaime Y CALMON, Pedro: "Brasil" en: Histmia de America y de los pueblos americanos, dirigida porAntonio Ballesteros e Beretta. T. XXVI, Salvat Editores, S.A.. Barcelona, 1956. p. 544 a 545. 
de alguna manera, permitió que la presencia portuguesa en la zona continuara bajo otros condicionamientos, facilitando el reacomodamiento de los

\section{Fuentes}

Documentos inćditos:

ARCHIVO GENERAL DE LA NACIÓNARGENTINA (A.G.N.).

Sala IX. División Colonia, Sección Gobierno, Interior y Hacienda.

Documentos ćditos:

DOCUMENTOS PARA LA HISTORIA ARGENTINA; ToIno V, Comercio de Indias, Antecedentes Legales (1713-1778). Facultad de Filosofía y Letras. Universidad de Buenos Aires, Buenos Aires, 1915.

MEMORIAS DE LOS VIRREYES DEL RIO DE LA PLATA. Buenos Aires, Bajel.

TRATADO PRELIMINAR SOBRE LOS LIMITES DE LOS ES. TADOS PERTENECIENTES A LAS CORONAS DE ESPAÑA Y PORTUGALEN LAAMERICAMERIDIONAL AJUSTADO Y CONCLUIDO EN SAN LORENZOA II DE OCTUBRE DE 1777. En: ANGELIS, Pedro: Coleccioin de Obras y Documentos relarivos a la Historia Antigaa y moderna de las Provincias del Rín de les Plana. Con prologo y notas de Andrés M. Carretero. Buenos Aires, Editorial Plus Ultra, 1970. T. V. p. 219 a 2.37.

\section{Bibliógrafia}

ALBUQUERQUE, Manuel Mauricio de. Pequeña historia de la formacion social brasileña. Rio de Janeiro, Graal Janeiro, 1984.

BARBA, E.M.: "Sobre el contrabando en la Colonia del Sacramento (siglo XVIII)". En: Imverrigaciones y Ensayos. $\mathrm{N}^{\circ} 28$, Buenos Aires, Acadeınia Nacional de la Historia, 1980. antiguos intereses lusitanos en el área y favoreciendo la vigencia de una problemática que se pretendía haber concluido.

BENTANCUR, Arturo A. Don Cipriano de Melo, señor de firmteras. Montevideo, Arca, 1985.

CANABRAVA.A. P.. O comencio portugués no Rio da Prata (1580. 1640). San Pablo, Ed. Itatiaja y Univ. de San Pablo, 1984.

CARCANO, Miguel A. La politica internacional en la historia argentima. Libro I: Del descubrimiento a la emancipacion. 1516-1810. Buenos Aires, Eudeba, 1972.

CORTESĀO. Jaime y CALMON, Pedro. "Brasil" En: BALLESTEROS y BERETTA, Antonio Historia de America y de los pueblos americanos. T. XXVI, Barcelona, Salvat Editores, 1956.

MEDEIROS DOS SANTOS, Corcino. Ecomomía y sociedad do Rio Grumde do Sul. Século XVIII. San Pabio, Companhia Editora Nacional, 1984.

NOVAIS, Fernando A. Portugal y Brasil en la crisis del antiguo sistema colonial (1777-1808). San Pablo, Editora Hucitec, 1989.

SEGRETI, C.S.A. Temas de Historia Colonial (comercio e injerencia extranjera). Buenos Aires, Academia Nacional de la Historia, 1987.

SILIONI. Rolando S. La diplomacia luso-brasileña en la cuenca del Plara. Buenos Aires, Círculo militor, 1964.

SILVA. Hernín A. El comercio entre España y el Río de la Plata. (1778-18/0). España. Banco de España. Servicio de Estudios. Estudios de Historia Económica. N226, 1993.

STUDER. E.F.S. de. La trata de negros en el Río de la Plata durante el sigho XVIII. Buenos Aires. Universidad de Buenos Aires, Departamento Editorial, 1958.

VILLALOBOS, Sergio. El comercio y la crisis colonial. Santiago de Chile, Editorial Universitaria. 1990.

Endereço da Autora: Departamento de Huınanidades - Universidad Nacional del Sur • 12 de Octubre y San Juan • (8000) Bahía Blanca - Pcia. de Buenos Aires - República Argentina

Domicilio part.: O'Higgins 1350 • (8000) Bahía Blanca • Pcia. de Buenos Aires - República Argentina 